\title{
Knowledge Creation Through Engagement in a Personal Learning Environment
}

\author{
Mary P. Welsh \\ Department of Childhood and Primary Studies \\ University of Strathclyde \\ Glasgow G13 1PP, UK. \\ mary.welsh@strath.ac.uk
}

\begin{abstract}
This paper reports on an action research project involving a complete re-design of a module in Educational Studies undertaken by students in the first year of a B.Ed degree in a university in Scotland. Innovative use of a personal learning environment (PLE), the PebblePad E-Portfolio System, resulted in radical changes in teaching, learning and assessment and produced significant gains in learning and in efficient, effective use of staff time. The lecture programme was restructured in a way that identified five clear, natural breaks, which were named "learning milestones". These occurred at the end of each "mini-series" of lectures. A "core task", designed to consolidate the learning content of each mini-series, was constructed by the faculty member who had delivered the lectures and formative assessment, in the form of self and peer-based assessment, was designed around these core tasks, allowing an incremental increase in the demands placed on students. The project supported the development of skills of self and peer-based formative assessment, reflection and self-regulation in students aiming to be primary (elementary) school teachers. The intervention was funded by the Re-Engineering Assessment Practices in Higher Education (REAP) Project which, in turn, received funding from the Scottish Executive (Government) E-Transformation Initiative.
\end{abstract}

\section{Introduction}

In recent years, trends identified in the early sixties and seventies, by commentators such as Umesao [1], Bell [2], and Touraine [3] have come to fruition. We live in an age in which employment is now centred on the service sector rather than the primary and secondary sectors; scientific work, research and development have gained in importance; employers now engage workers for their intellectual capacities rather than their capability to engage in manual labour and, finally, importantly, information and knowledge have become as important, or it could be argued, even 
more important to production than land and labour. We live in the age of the knowledge society where knowledge is a commodity to be developed, bought and sold as part of a global economy. Governments worldwide have been forced to consider how best they can provide their citizens with the knowledge, skills and training essential to success in this global economy.

One result of this global movement has been an increased desire to widen access to higher education, and for teaching, learning and assessment to adopt more student centred approaches. The language commonly used in government policies seeks the creation of "... successful learners, confident individuals, responsible citizens and effective contributors ..." [4]. Approaches include increased use of formative assessment strategies and evidence based learning supported by the development of new environments for learning and knowledge creation.

In many institutions information and communications technology (ICT) has been harnessed as a tool for supporting student learning; for storing evidence of student attainment; and for facilitating the development of reflective, self-regulated learners with the skills necessary for success in the knowledge society. One important growth area has been the development and implementation of managed learning environments (MLEs), virtual learning environments (VLEs) and personal learning environments (PLEs). Strategies supporting use of such tools have been adopted in the United States, Canada, Australasia, Scandinavia and the countries of the European Community (EC). Increasingly, [5-9], e-portfolios, an important subset of PLEs, are being used as tools for assessment, not just as depositories of evidencelinked materials. Innovative use of e-portfolios to promote formative assessment, in particular self- and peer-based assessment, is the focus of this paper.

\subsection{Strategic learning design}

The main strategy introduced in this project was one which empowered students to assume responsibility for their own learning. Research in this domain, [10-12], has identified that this notoriously difficult to establish, especially in first year undergraduate study.

The team introduced a learning design based on use of formative assessment to support development of reflection and self-regulation and to allow this to be used as an integral part of the learning process itself. Increasing evidence from literature, [13-19], supported this innovation.

Three main research questions emerged from review and critical analysis of relevant literature and from previous experience of teaching on the module:

- How can we change the assessment system to improve the learning experience of students?

- How can we modify the leaning environment?

- How can we offer timely, high-quality feedback to support student learning and achievement? 


\subsection{Elements of the intervention}

The module discussed here was part of a first year degree course and was designed to provide students $(n=175)$ with an introduction to issues surrounding learners and learning. Students maintained a portfolio recording their engagement with module content which was submitted to tutors for formative evaluation at a mid-point during the academic year. Those who were failing to reach a satisfactory level at this point were offered guidance on how to improve attainment. Tutors were increasingly concerned by a lack of engagement with module content and disappointing quality of resulting student work. There was a perception of mismatch between requirements for final summative assessment and work expected from students during the module. In line with principles of "constructive alignment", Biggs [20], the module underwent a radical re-design. Previously students attended a series of twenty lectures and follow-up tutorials, given by various faculty staff, some of whom were also involved in the delivery of the lectures. During this action research project the lecture programme was restructured in a way that identified five clear, natural breaks, which were named "learning milestones". These occurred at the end of each "mini-series" of lectures. A "core task", designed to consolidate the learning content of each "mini-series", was constructed by the faculty member who had delivered the lectures. Formative assessment was designed around these core tasks and allowed an incremental increase in the demands placed on students. The tasks were spread evenly throughout the year and helped students develop critical skills through consideration of differing theoretical perspectives on learners and learning. A self and peer assessment methodology was adopted as the basis for formative assessment associated with each core task and a commercially produced e-portfolio system, 'PebblePad', already being introduced in other parts of the course, was adopted as the medium through which the formative assessment strategy could be implemented. It was intended that this would also facilitate links between other course modules.

To maximise the effectiveness of tutor feedback, this was provided to only one subgroup in a tutor's class following each core task submission. Students were then invited to participate in further peer analysis and interpretation of both the submission and its tutor feedback. This promoted development of essential, professional reflective skills and empowered students who were working towards a common future goal.

\section{A New Model for Learning}

Whilst researching an effective framework to support the intervention, the team considered the work of many researchers in the field. However, it was the work of a researcher from their own institution, Nicol [18-21], which provided a viable framework - detailing ten principles of good assessment and feedback analysed over two dimensions [Nicol 19].

An examination of Nicol's principles 2, 3, and 6, gave rise to the following interpretations and form the focus of the remainder of this paper:

Encourages 'time and effort' on challenging learning tasks. 
It was recognised that 'time and effort' on the incrementally challenging learning tasks must be distributed evenly throughout the course. Students in each tutor group of 25 students were allocated to sub-groups comprising a maximum of five students. Core tasks were issued at least four weeks before the submission date for each core task final response, and students were free to offer feedback to sub-group peers during this period. Students were trained in use of the "Two Stars and a Wish" formative assessment strategy which invites individuals to comment on two sections of a response that he/she thinks have been completed well and one section which requires some improvement. An evaluator normally offers some guidance on how this improvement might be achieved or, at the very least, offers comments to prompt consideration of possible solutions. Students were given guidance on appropriate register and vocabulary to use and were advised that this strategy was appropriate for learners at all stages. It was hoped that this process would lead to in-depth discussion of the issues and facilitate deep, rather than surface, learning. It was essential also that a spirit of mutual respect be established.

Submission of core task responses to the e-portfolio environment was therefore developed as a two-stage process. First of all, students were required to post their personal response to the core task to the system, for peer scrutiny and feedback. In the second stage, the sub-group met, face-to-face, or online, to synthesise their group response based on individual responses. The same assessment strategy was recommended to facilitate discussion and allow work to be selected for inclusion in the group portfolio submission.

Deliver high quality feedback information that helps learners self-correct.

Some researchers have questioned the ability of students to offer good quality feedback to peers, however Boud [13], argues that the most effective way of making students "close the loop", Sadler [23], in the "task-performance-feedback" cycle is to allow students to re-submit work after receiving feedback and before moving on to the next task. Nicol and MacFarlane-Dick [21], highlight the importance of offering good quality, timely feedback, based on self-regulation. Participants valued both the feedback offered and the opportunity to re-submit, albeit in an altered form. Engagement in a common task enabled students to identify areas of difficulty for peers and to offer supplementary, often contrasting, views of the issue. This contributed to a process of social construction of knowledge and facilitated the development of communal constructivism in which group synthesis responses were stored in the e-portfolio system to be shared by all students in each large tutor group. Facilitates the development of self-assessment and reflection in learning.

Since the inspirational American philosopher Dewey [22-24] first discussed the importance of reflection for personal and professional growth, educationalists have striven to promote this activity among future, and current, educational professionals [25-30]. Reflection on experience prompts action and results in the development of professional skills, knowledge and understanding and is conceived as one of the hallmarks of a professional practitioner. Through participation in the peer assessment process, this project promoted development of reflection and resulted in an improvement in the quality of written work.

There was no suggestion that the intervention would lead to a predominantly elearning approach or that traditional approaches to lectures or tutor led seminars would be abandoned. What has now become clear, however, is that the new blend of 
methodologies has had a feedback effect leading to subtle and sometimes significant, changes in normal operational practice across the whole range of learning experiences. Not only has the adoption of the particular blend improved the quality of student engagement and learning, but it also enabled significant savings in staff time, both in the seminar programme and in the time devoted to assessment activities. This will be discussed further.

\subsection{Research Methodology}

Action research, with its emphasis on emancipatory involvement in a practitioner setting, through a cyclical process of continual reflection and refinement, was identified as being an appropriate approach for this project [Robson, 31]. A case study evaluation [Robson, 31], with its emphasis on in-depth study of a particular case, supported by engagement with materials gleaned from a range of sources, was deemed a suitable framework for reporting the project. This paper is the result.

\subsection{Data Collection and Analysis Research Methodology}

A mixed-method approach to data collection allowed both quantitative and qualitative data to be collected and subsequently analysed. Previously evaluation of the module was carried out using a single questionnaire, issued to all students, following the final summative exam. During this project, at the end of the second semester, three weeks before the final summative exam, a modified version of the previous questionnaire was issued. This version was used in order that some comparisons might be made. Data from the questionnaire was subjected to descriptive statistical analysis, using SPSS, by a member of the module research team.

The external REAP evaluation team administered another questionnaire also on the same occasion. This was developed and analysed independently by the evaluators who later conducted focus group meetings, one for students (course student representatives), and one for staff (volunteers, excluding members of the research team), where participants offered opinions on all aspects of the course. This data was also made available to the project research team.

\section{Findings and Conclusions}

The concepts underpinning the whole process have been the subject of considerable discussion and reflection. Findings from focus groups and questionnaires have shown that, overall, the students were positive about this learning experience with the majority of students (72.3\%) agreeing that group tasks supported their learning. 
Table 1. The group tasks supported my learning

The group tasks supported my learning

\begin{tabular}{|ll|c|c|c|c|}
\hline & Frequency & Percent & Valid Percent & $\begin{array}{c}\text { Cumulative } \\
\text { Percent }\end{array}$ \\
\hline Valid & Strongly Agree & 20 & 17.4 & 17.9 & 17.9 \\
& Agree & 61 & 53.0 & 54.5 & 72.3 \\
& Neutral & 19 & 16.5 & 17.0 & 89.3 \\
& Disagree & 7 & 6.1 & 6.3 & 95.5 \\
& Strongly Disagree & 5 & 4.3 & 4.5 & 100.0 \\
& Total & 112 & 97.4 & 100.0 & \\
Missing & 999 & 3 & 2.6 & & \\
Total & 115 & 100.0 & & \\
\hline
\end{tabular}

Nevertheless, significant anomalies remain. In spite of $67.5 \%$ of respondents finding peer feedback helpful, only $50.9 \%$ found group feedback, offered by tutors, relevant to their own work! This would seem to imply that the students themselves have assumed the role of tutors for peers and are perceived as effective in that role.

Table 2. I found the feedback from peers helpful

I found the feedback from peers helpful

\begin{tabular}{|c|c|c|c|c|c|}
\hline & & Frequency & Percent & Valid Percent & $\begin{array}{c}\text { Cumulative } \\
\text { Percent }\end{array}$ \\
\hline \multirow[t]{6}{*}{ Valid } & Strongly Agree & 18 & 15.7 & 15.8 & 15.8 \\
\hline & Agree & 59 & 51.3 & 51.8 & 67.5 \\
\hline & Neutral & 28 & 24.3 & 24.6 & 92.1 \\
\hline & Disagree & 7 & 6.1 & 6.1 & 98.2 \\
\hline & Strongly Disagree & 2 & 1.7 & 1.8 & 100.0 \\
\hline & Total & 114 & 99.1 & 100.0 & \\
\hline Missing & 999 & 1 & .9 & & \\
\hline Total & & 115 & 100.0 & & \\
\hline
\end{tabular}

Open responses in the questionnaire indicated that peer based formative assessment had been effective in promoting reflection and self-regulation. Typical comments were:

"I liked working in groups for the core tasks. It helped me to understand things better when the group discussed it and bounced ideas off each other."

"The group work really helped me further my development and development of the content."

However there are still some challenges. $52.7 \%$ of respondents either "Strongly Agreed" or "Agreed" that use of the e-portfolio environment to support the blended learning approach made an impact on their ability to engage in the course at a distance, but only $23.5 \%$ said it helped them organise their course work. Awareness of the wider benefits of blended learning and of ubiquitous PLE, or e-portfolio, systems appears still to be lacking and requires further research.

Furthermore, in spite of better exam results (unknown at the time of the survey), and increased engagement in course materials, some students were still unsure of the 
benefits of formative assessment - only 51.3\% either "Agreed" or "Strongly Agreed" that this method was beneficial.

It is evident that student engagement in different aspects of the course has varied considerably. The research team is considering how these variations in experience might be minimised and welcomes input from interested parties.

Students on this module have generally felt empowered, but there are some for whom the process has been painful,

"I appreciate the necessity and advantages of working in groups, but this only works if all groups have the same commitment and level of input. Group work does not place the same incentive to study as individual work which is submitted and assessed individually." (Student aged 39+).

To maximise the impact of these developments, education institutions must find ways of promoting formative assessment to improve effectiveness of student learning and also to achieve efficiency gains in the deployment of staff. Skills, which encourage the social construction of knowledge and understanding, leading to collective intelligence, must be developed throughout courses and modules must provide opportunities for students, and staff, to develop knowledge, skills and understanding of the entire learning process and of metacognition. In this project, despite student fears about lack of preparation for the final summative exam, the arithmetic mean score for the written section rose from 59\% in the academic year 2005-2006 to 70\% in the 2006-2007. Peer based formative assessment has been seen to bring about learning, social and professional gains for all involved.

The use of blended learning, described above, is to support the development of reflective, self-regulated classroom practitioners, skilled in formative assessment strategies and the pedagogy of effective e-portfolio use require further research and development. The role of innovative learning environments is to support these developments.

\section{References}

1. T. Umesao, Information Industry Theory Dawn of the Coming Era of the Ectodermal Industry. Hoso Asahi, Jan. pp. 4-17, Tokyo: Asahi Hoso (1963).

2. D. Bell, The Coming of Post-Industrial Society (Heinemann, London, 1973, 1999).

3. A. Touraine, The Post Industrial Society Tomorrow's Social History, Classes, Conflicts and Culture in the Programmed Society (English Edition) Translated by L. Mayhew. (Wildwood House, London, 1994).

4. Scottish Executive, A Curriculum for Excellence (Edinburgh, HMSO, 2004).

5. C. Bailey et al., Lifelong learner records to support eLearning. Conference presentation. http://www.alt.ac.uk/altc2004/timetable/abstract.php?abstract_id=153) (2004).

6. B. Collis, The Contributing Student: A blend of pedagogy and technology, in J. Copsey (ed.) The Next Wave of Collaboration, Auckland, New Zealand: Educause and The University of Auckland Library, 7-12 (2005).

7. L.A.J. Stefani \& S. Diener, The e-Teaching portfolio as a tool to promote professional development, proceedings of Educause, ISBN 0 86869-108-9. (2005).

8. M.B. Ross and M. Welsh, Formative Feedback to Improve Learning on a Teacher Education Degree Using a Personal Learning Environment, proceedings of ICBL, 2007, Brazil. ISBN 978-3-89958-277-2. 
9. M.B. Ross and M. Welsh, M. (2007). Formative Feedback to Improve Learning on a Teacher Education Degree Using a Personal Learning Environment, International Journal of Emerging Technologies in Learning (i-Jet), 2 (3), (2007) ISSN: 1863-0383.

10. D. Nicol, Increasing success in first year courses assessment re-designs selfregulation and learning technologies. Proceedings of ASCLITE Conference, Sydney, Dec 3-6, 2006.

11. M. Yorker, Leaving Early Undergraduate Non-completion in Higher Education (Flamer, London, 1999).

12. M. Yorker and B. Long den, Retention and Student Success in Higher Education (Flamer, London, 2004).

13. D. Bound, Sustainable Assessment: rethinking assessment for the learning society. Studies in Continuing Education, 22(2), 151-167 (2000).

14. P. Black and D. Wiliam, (1998). Assessment and Classroom Learning. Assessment in Education, 5(1), 7-74.

15. A. Brew, Towards autonomous assessment: using self-assessment and peer assessment, in S.Brown and A. Glaser (eds) Assessment Matters in Higher Education: Choosing and Using Diverse Approaches (Open University Press, Buckingham, 1999) pp. 159-171.

16. N. Falchikov, Improving Assessment Through Student Involvement Practical Solutions for Aiding Learning in Higher and Further Education. (RoutleldgeFalmer, London, 2005).

17. G. Gibbs and C. Simpson, Conditions Under Which Assessment Supports Students' Learning. Learning and Teaching in Higher Education (1), 3-31 (2004).

18. D. Nicol and C. Milligan (2006). Rethinking technology-supported assessment practices in relation to the seven principles of good feedback practice. In C. Bryan \& K. Clegg (Eds.), Innovative Assessment in Higher Education (Routledge, London, 2006), pp. 64-77.

19. D. Nicol, Principles of good assessment and feedback: Theory and practice. From the REAP International Online Conference on Assessment Design for Learner Responsibility, 29th-31st May, 2007. Available at http://ewds.strath.ac.uk/REAP07 (2007).

20. J. Biggs, Teaching for Quality Learning at University (Second ed.). (SRHE/Open University Press, London, 2003).

21. D. J. Nicol and D. Macfarlane Dick, Formative assessment and selfregulated learning: a model and seven principles of good feedback practice. Studies in Higher Education, 31(2), 199-218 (2006).

22. J. Dewey, How We Think (D.C. Heath, Chicago, 1910).

23. J. Dewey, How We Think: A Restatement of Reflective Thinking to the Educative Process (Henry Regnery, Chicago, 1933).

24. J. Dewey, Experience and Education (Collier Books, New York, 1938).

25. L. Stenhouse, An Introduction to Curriculum Research and Development (Heinemann. London, 1975).

26. W. Carr and S. Kemmis, Becoming Critical: Education, Knowledge and Action Research (Falmer/Deakin University Press, Lewes, 1986).

27. J. Elliot, Action Research for Educational Change (Open University Press, Buckingham, 1991).

28. D. Schon, The Reflective Practitioner How Professionals Think in Action (Basic, London, 1983).

29. K. Zeichner, and D. Liston, Reflective Teaching An Introduction (L Erlbaum, Mahwah, N.J., 1996)

30. R.A. Pring, The Philosophy of Educational Research (Continuum, London, 2000).

31. C. Robson, Real World Research (Second ed.). (Blackwell, Oxford, 2002). 